\title{
Comparison of real driving cycles and consumed braking power in suburban Slovakian driving
}

\author{
Tsvetomir Gechev ${ }^{1, *}$, Martin Mruzek ${ }^{2}$, and Dalibor Barta ${ }^{3}$ \\ ${ }^{1}$ Technical University - Sofia, Faculty of Transport, 8 Kliment Ohridski Blvd., Block 9, 1000 Sofia, Bulgaria \\ ${ }^{2}$ University of Žilina, University Science Park, Univerzitná 1, 01026 Žilina, Slovakia \\ ${ }^{3}$ University of Žilina, Faculty of Mechanical Engineering, Univerzitná 1, 01026 Žilina, Slovakia
}

\begin{abstract}
The paper compares the features of suburban real driving cycles performed with CORRSYS DATRON measurement equipment on routes in the region of Žilina, Slovakia. It observes differences in the maximum and average vehicle velocities and the amount of braking in relation to the elevation profile of each individual cycle. Consumed braking power was also calculated in the different cycles in order to review the potential electricity regeneration capabilities of hybrid electric vehicles, operating on the same routes. The change in braking energy depending on vehicle mass and presence of grade on the routes in the measured cycles was also assessed. The calculations and plotting were done by using Matlab software.
\end{abstract}

\section{Introduction}

Nowadays researchers and automobile producers come together in search of a way to increase the efficiency of vehicles by mastering or changing the technology and concepts incorporating the idea of modern transportation. This is due to the substantial usage of internal combustion engine (ICE) powered automobiles, which are the major cause of many environmental and health problems.

Electric vehicles (EVs) and hybrid electric vehicles (HEVs) are some of the main proposals that are to replace conventional vehicles and achieve a clean and highefficient future transportation [1].

The adaptation of such vehicles would have a significant environmental benefit. It is because EVs and HEVs use electricity, generated by various sources, many of which are renewable. In France alone, where most of the electricity is produced from nuclear energy, the percentage of emissions would fall down considerably if EVs were to be used massively [2].

The efficiency of EVs is currently lower than that of conventional gasoline and diesel driven ICE automobiles but there are tremendous reserves in terms of future enhancement of the performance of such vehicles [3]. One such important feature of HEVs and EVs is their ability to recover kinetic energy from braking by using their electric motors as generators. For example, braking a $1500 \mathrm{~kg}$ vehicle from $100 \mathrm{~km} / \mathrm{h}$ to 0 dissipates about $0,16 \mathrm{kWh}$ of energy [1]. It could potentially be stored and reused thus making the vehicle more energy efficient.

Automobile energy consumption could be calculated by the use of driving cycles, therefore this principle is also suitable for estimation of the energy regeneration potential of HEVs and EVs.
The New European Driving Cycle (NEDC) acts as a simulation tool for the typical usage of a car in Europe. It is a standardized test applied in EU member states to enable comparability in results. However, the current NEDC is not representative of the present-day practical transportation conditions, but it is rather an old-dated pattern with low accelerations and many constant speed sections [4]. This paper presents real driving cycles performed on suburban roads by a contemporary conventional vehicle. The aim of the paper is to compare the features of the measured cycles and determine the amount of braking energy, potentially recuperated by the application of HEVs in short distanced suburban Slovakian driving.

\section{Equipment}

A typical commuter vehicle - Hyundai ix20 (Fig. 1), with the following characteristics (Table 1) was used for the measurement of the real driving cycles.

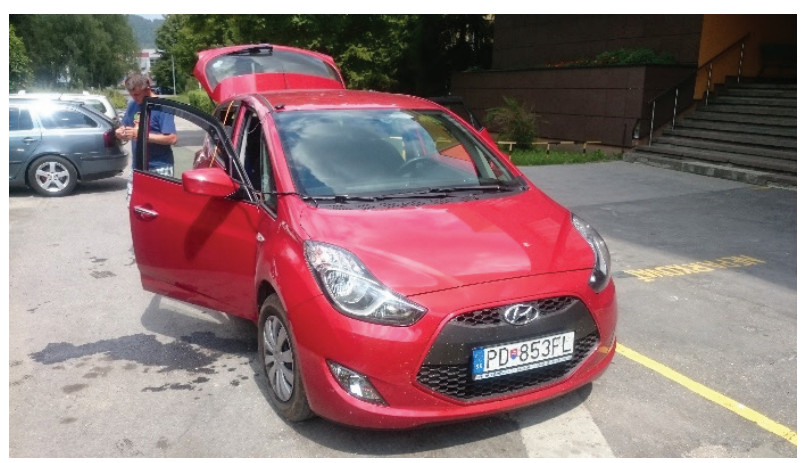

Fig. 1. Hyundai ix20 test vehicle.

\footnotetext{
${ }^{*}$ Corresponding author: tsv.gechev@,gmail.com
} 
Table 1. Vehicle characteristics.

\begin{tabular}{|l|l|}
\hline Engine displacement, $\mathrm{dm}^{3}$ & 1,591 \\
\hline Power, $\mathrm{kW}$ & 91,5 \\
\hline Fuel type & gasoline \\
\hline Air drag coefficient, - & 0,3 \\
\hline Curb weight, kg & 1255 \\
\hline Total permissible mass, $\mathrm{kg}$ & 1710 \\
\hline Max speed km/h & 185 \\
\hline Torque, $\mathrm{Nm}$ & $156 / 4200 \mathrm{rpm}$ \\
\hline Width, $\mathrm{m}$ & 1,765 \\
\hline Height, $\mathrm{m}$ & 1,6 \\
\hline
\end{tabular}

The measurement equipment consists of a DAS 3 unit with a contactless sensor based on the Doppler phenomenon used for the metering of time, velocity, acceleration and distance (Fig. 2), and a CORRSYS DATRON force pedal sensor (Fig. 3). The road grade is estimated with a GPS receiver (Fig. 3).

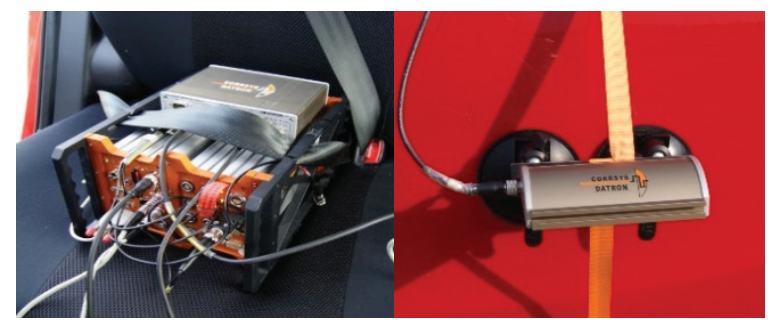

Fig. 2. DAS 3 unit (left) with a contactless sensor (right).

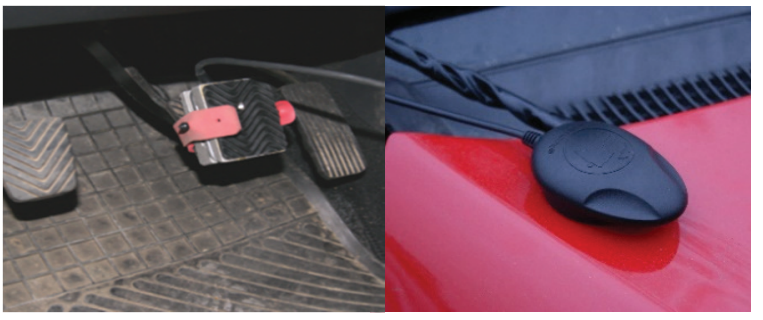

Fig. 3. CORRSYS DATRON force pedal sensor (left) and GPS receiver (right).

The total weight of the measurement equipment, passengers and their luggage is $241 \mathrm{~kg}$.

\section{Cycle measurement and comparison}

\subsection{Cycle overview}

The city of Žilina is a big industrial and services center in northwestern Slovakia. It is situated at a crossroad and it offers many professional and educational opportunities. As a result there is a big number of commuters and students travelling each day or week from the neighboring small cities and villages in the region to Žilina.

On account of that, the vehicle was driven on two different suburban road sections: Žilina - Rajecke Teplice and Žilina - Terchova, in each respective direction, measuring four cycles with different characteristics (Fig. 4 - Fig. 7). The vehicle was driven on workdays (not in commuter trip peaks) according to the traffic requirements. The measured cycles were produced independently and could be used for simulation of various types of vehicles. The velocity values were filtered with a Savitzky - Golay filter in a Matlab environment in order to eliminate fluctuations and noise. Additionally, all plotting and calculations were done in Matlab.

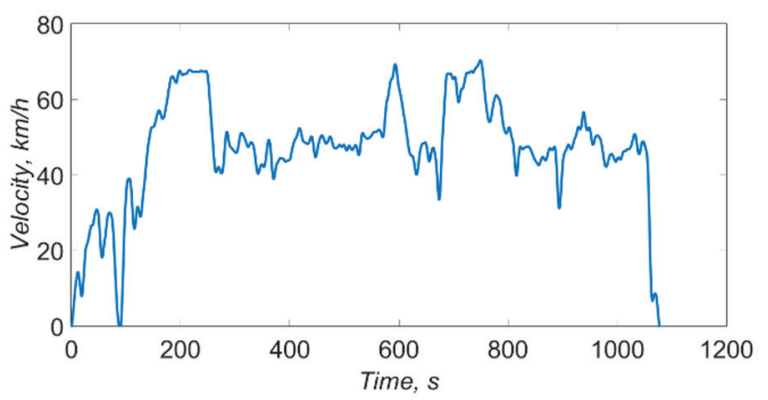

Fig. 4. Driving cycle Žilina - Rajecke Teplice.

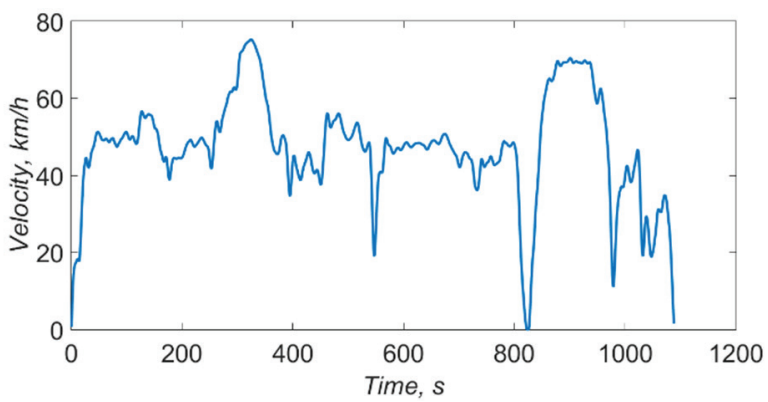

Fig. 5. Driving cycle Rajecke Teplice - Žilina.

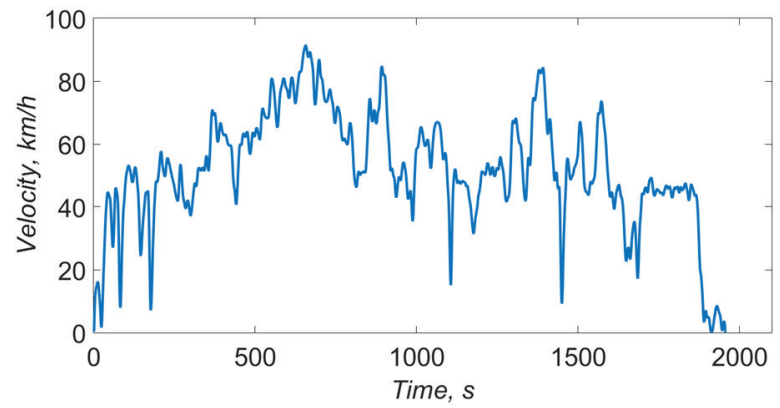

Fig. 6. Driving cycle Žilina - Terchova.

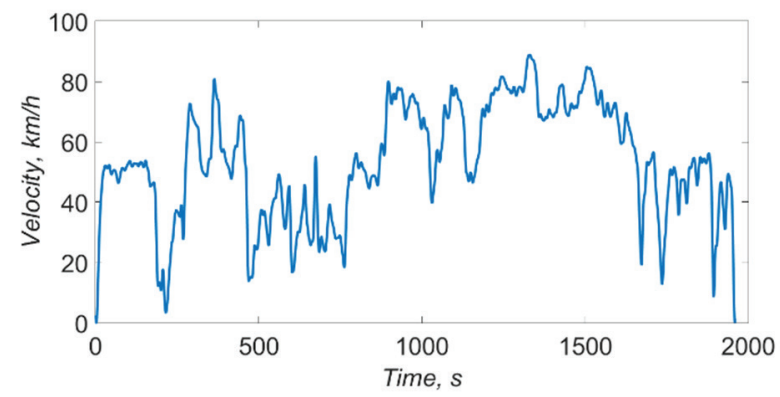

Fig. 7. Driving cycle Terchova - Žilina.

The cycles characteristics are displayed in Table 2. It can be seen that the average and maximum velocities are different. This is due to the fact that Rajecke Teplice is closer to the center of Žilina (14 km away as compared to $29 \mathrm{~km}$ to Terchova) and the traffic is denser. Additionally, the route to Rajecke Teplice goes through two big villages (compared to 3 of a moderate size on the way to Terchova) which results in more speed limitations. Despite the 
difference, the values are very close which shows that the conditions in which the cycles were measured are comparable.

Table 2. Cycle characteristics

(F4 to F7 correspond to Fig.4 to Fig. 7).

\begin{tabular}{|l|c|c|c|c|}
\hline Cycle & F4 & F5 & F6 & F7 \\
\hline Max velocity, km/h & 70,4 & 75,3 & 91,3 & 88,7 \\
\hline Average velocity, km/h & 46,9 & 47,1 & 50,7 & 52,6 \\
\hline Distance, km & 14 & 14,2 & 28,2 & 29,1 \\
\hline Duration, min & 17,9 & 18,1 & 32,6 & 32,6 \\
\hline Denivelation, m & \multicolumn{2}{|c|}{72,2} & \multicolumn{2}{|c|}{206} \\
\hline Braking time, \% of total & 4,1 & 4,7 & 3,22 & 4,53 \\
\hline Idle time, \% of total & 0,46 & 0,36 & 0 & 0,25 \\
\hline
\end{tabular}

Even though the cycles were not performed during traffic peaks, it is obvious from Fig. 4 and Fig. 5 that there could be rapid brake patterns dropping the vehicle speed to 0 in suburban traffic.

One of the most varying factors affecting the vehicle driving pattern and therefore the amount of braking is the road elevation profile (Fig. 8 and Fig. 9).

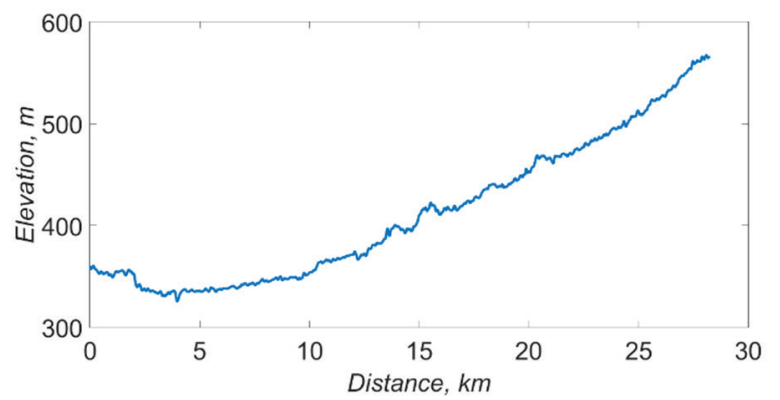

Fig. 8. Elevation profile Žilina - Terchova.

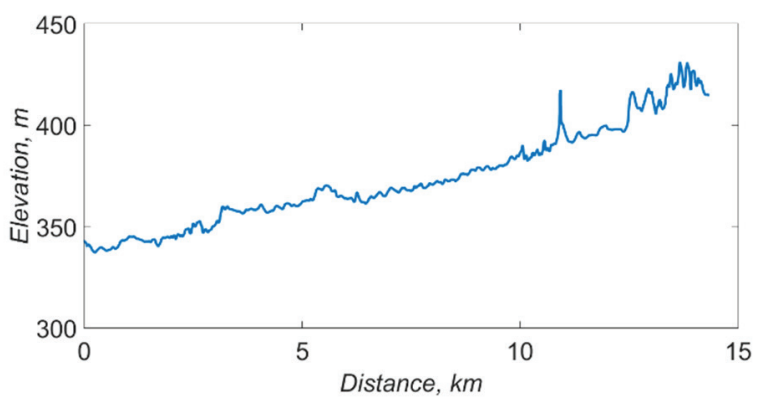

Fig. 9. Elevation profile Žilina - Rajecke Teplice.

The braking time data from Table 2, measured by the pedal force sensor, shows that cycle F7 has more braking time as a percentage of the whole driven time than the F6 cycle. This can be explained by the elevation profile (Fig. 8), which downgrades significantly in the direction Terchova - Žilina. The same applies for the comparison between cycles F4 and F5. The smaller change in the braking time percentage compared to the one in cycles F6 to F7 indicates smaller value differences in the braking energy between the uphill and downhill patterns.

\subsection{Comparison of consumed braking power}

The results of the driving cycles analysis show moderate height differences in the elevation profiles, which entails higher values of both tractive and braking energy consumption as compared to the ones measured on flat road. The required vehicle power, the braking and tractive energy dissipation are calculated based on the selected car parameters and the real driving cycles [5].

Vehicle force balance is given in (1) and presents the forces of aerodynamic drag resistance, inertia, grading resistance and rolling resistance, where $\psi$ is the road resistance coefficient (2), $f$ is the rolling resistance coefficient (3), $G$ is the weight force, $V$ is vehicle velocity, $W$ is the coefficient of drag flow (4), $a$ is vehicle acceleration and $\delta$ is the rotating parts' inertia coefficient (5) [6].

$$
\begin{gathered}
F=\psi G+W V^{2}+\frac{\delta G}{g} a, \mathrm{~N} . \\
\psi=f \cos \alpha \pm \sin \alpha . \\
f=f_{0}+V^{2} \cdot 6,5 \cdot 10^{-6} . \\
W=0,5 C_{x} \rho S, \text { N. } \mathrm{s}^{2} / \mathrm{m}^{2} . \\
\delta=1+\sigma_{1}+\sigma_{2} \cdot i^{2} .
\end{gathered}
$$

The rolling resistance coefficient at low speed $f_{0}=$ 0,011 corresponds to an asphalt road with moderate grip capabilities. Vehicle frontal area $S=0,8 H B$ where $H$ and $B$ are vehicle height and width [6]. The rotating parts inertia coefficient $\delta$ is calculated on the basis of approximate estimation of the current shifted gear depending on the vehicle speed. Coefficients $\sigma_{1}$ and $\sigma_{2}$ are equal to 0,04 [6]. Table 3 shows the vehicle gear ratios and gear speed ranges. Idle time in all measured cycles is close to zero, therefore non-gear vehicle operation times can also be considered insignificant. The driver did not shift out of gear while driving in suburban traffic.

Table 3. Estimation of inertia from rotating parts.

\begin{tabular}{|c|c|c|c|}
\hline Gear № & Gear ratio $\boldsymbol{i}$ & Est. speed & $\boldsymbol{\delta}$ \\
\hline 1 & 3,615 & $0-15$ & 1,56 \\
\hline 2 & 1,955 & $15-30$ & 1,19 \\
\hline 3 & 1,370 & $30-40$ & 1,11 \\
\hline 4 & 1,036 & $40-50$ & 1,08 \\
\hline 5 & 0,893 & $50-70$ & 1,07 \\
\hline 6 & 0,733 & $70+$ & 1,06 \\
\hline
\end{tabular}

Multiplying (1) by the velocity gives the power output at driving wheels - (6) (Fig. 10) [6].

$$
P=V\left(\psi G+W V^{2}+\frac{\delta G}{g} a\right), \mathrm{W} .
$$

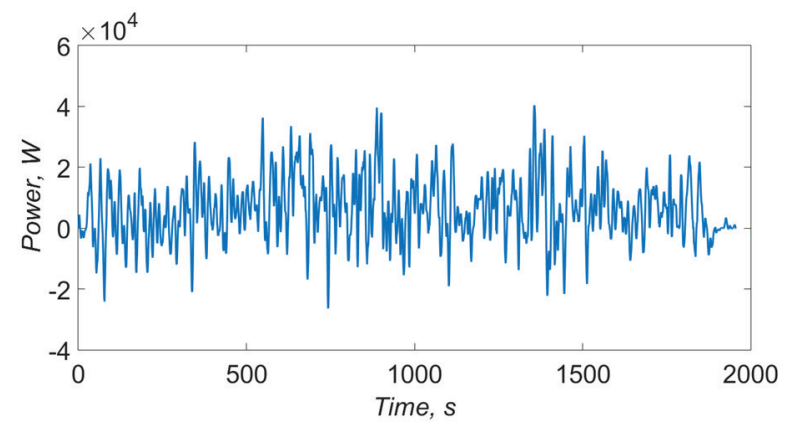

Fig. 10. Total power output, Žilina - Terchova. 
For $P>0$, the traction wheels accept power from the power plants and move the vehicle. In this situation, the braking power is zero. In contrast, when $P<0$ vehicle kinetic energy is dissipated by the brake system. In this case, the driving power is zero. Integrating equation (6) over the driving time can give the values of both traction energy (TE) and braking energy (BE) (Fig. 11) [1].

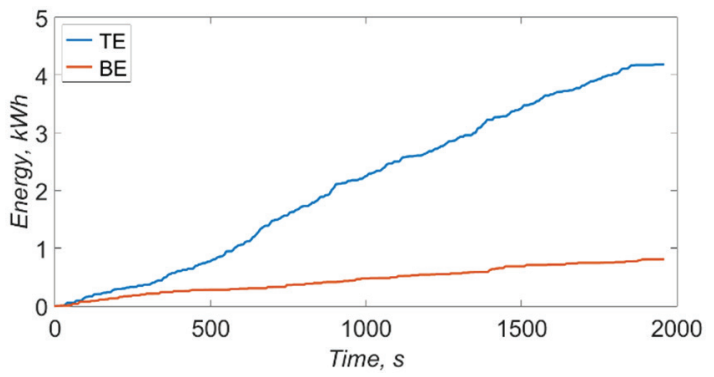

Fig. 11. Traction and braking energy dissipation over time, Žilina-Terchova (cycle F6).

The proper design and control of hybrid and electric vehicles, and more importantly, the design of automotive energy regeneration systems, depend on the amount of braking energy dissipated by a vehicle operating on certain road sections [1,7]. Data from all measured cycles is given in Table 4.

Table 4. Tractive and braking energy dissipation for each cycle.

\begin{tabular}{|l|c|c|c|c|}
\hline \multicolumn{1}{|c|}{ Cycle } & F4 & F5 & F6 & F7 \\
\hline Tractive energy, kWh & \multicolumn{4}{|c|}{} \\
\hline - Per cycle & 1,9 & 1,58 & 4,18 & 3,07 \\
\hline - Per km & 0,14 & 0,11 & 0,15 & 0,11 \\
\hline Braking energy, kWh & \multicolumn{5}{|l|}{} \\
\hline • Per cycle & 0,68 & 0,73 & 0,81 & 1,33 \\
\hline - Per km & 0,05 & 0,05 & 0,03 & 0,05 \\
\hline Percentage of BE to TE & 35,8 & 46,2 & 19,4 & 43 \\
\hline
\end{tabular}

When comparing cycles F4 and F5 it is important to note that cycle F4 has more consumed tractive energy due to the uphill characteristic of the road in the Žilina Rajecke Teplice direction. More braking time in F5 (Table 2) and the downhill pattern indicate a slightly higher braking energy consumption value of F5 as compared to F4 cycle, given the brake force was approximately equal. Cycles F6 and F7 have the same comparative assessment with F6 having higher tractive energy and lower braking energy consumptions than F7.

Logically, routes with elevation profiles have significantly more energy regeneration potential in downgrade sections with percentage of braking energy amounting up to $46 \%$ and $43 \%$ of the tractive energy in the measured real driving cycles (F5 and F7).

\subsubsection{Dependence of braking energy on vehicle mass and road elevation profile}

It is important to estimate the braking energy in its correspondence to vehicle mass and the route elevation (Fig. 12). For the first comparison the following set of masses was used (including luggage), $\mathrm{kg}$ : $m_{1}=1255+70+5=1330$ just a driver;

$m_{2}=1255+70+65+10=14002$ passengers;

$m_{3}=1255+70+65+65+15=14703$ passengers;

$m_{4}=1255+241=1496$ actual mass in measured cycles;

$m_{5}=1255+70+65+65+65+20=15404$ passengers;

$m_{6}=1710$ total permissible mass.

The bigger the vehicle mass is, the more braking power is put on the wheels (Table 5, Fig. 12). Consequently, there is more energy to be recuperated. Roads with change in the elevation also require more braking (Table 6).

Table 5. Change in kWh braking energy in relation to change of vehicle mass.

\begin{tabular}{|c|c|c|c|c|c|c|}
\hline$B E, \mathrm{kWh}$ & $m_{1}$ & $m_{2}$ & $m_{3}$ & $m_{4}$ & $m_{5}$ & $m_{6}$ \\
\hline $\mathbf{F 4}$ & 0,59 & 0,63 & 0,66 & 0,68 & 0,70 & 0,79 \\
\hline F5 & 0,64 & 0,68 & 0,72 & 0,73 & 0,76 & 0,85 \\
\hline F6 & 0,7 & 0,75 & 0,79 & 0,81 & 0,84 & 0,95 \\
\hline F7 & 1,15 & 1,22 & 1,3 & 1,33 & 1,37 & 1,56 \\
\hline
\end{tabular}

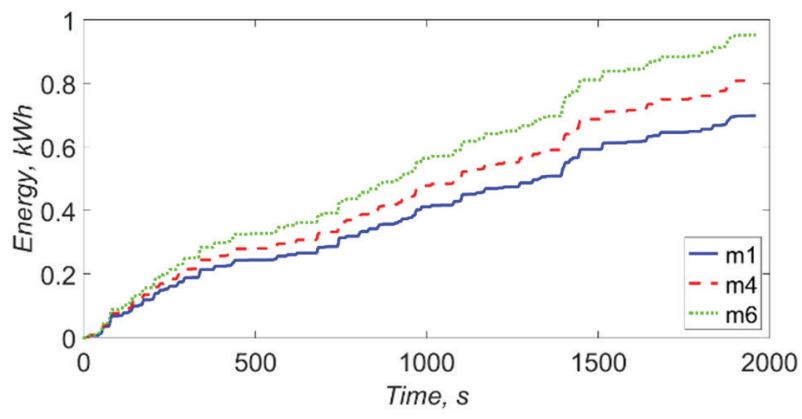

Fig. 12. Braking energy dependence on vehicle mass, Žilina Terchova.

Table 6. Change in kWh braking energy in relation to change of road grade.

\begin{tabular}{|c|c|c|c|c|}
\hline BE, $\mathrm{kWh}$ & $\mathrm{F} 4$ & $\mathrm{~F} 5$ & $\mathrm{~F} 6$ & $\mathrm{~F} 7$ \\
\hline Without grade & 0,21 & 0,22 & 0,57 & 0,54 \\
\hline With grade & 0,68 & 0,73 & 0,81 & 1,33 \\
\hline
\end{tabular}

\section{Conclusion}

The results show that standard commuter vehicles driven on suburban mountainous roads in the region of Žilina spend high amounts of braking power which then dissipates as braking energy in the form of heat.

The braking energy for some of the cycles comprises as much as $43 \%$ of the total tractive energy used - cycle F7, elevation difference $=206 \mathrm{~m}$, distance $\approx 28,5 \mathrm{~km}$. In this cycle, by driving on a graded route, the braking energy values could rise by as much as $146 \%$ (Table 6), measuring up to $1,33 \mathrm{kWh}$ in non-peak traffic situations, in comparison to non-graded routes of an equal distance. Additionally, the influence of the mass of the vehicle could increase the braking power by up to $35 \%$ at times when the vehicle operates at full mass load.

Conclusively, given the results, the usage of HEVs on mountainous suburban Slovakian roads by commuters is an appropriate measure to increase vehicle energy efficiency, to lower fuel costs and to ensure cleaner environment. 
This paper is supported by the project VEGA 1/0927/15 "Research of the use of alternative fuels and hybrid drives on traction vehicles with aim to reduce fuel consumption and air pollutants production".

This paper is supported by the following project: University Science Park of the University of Žilina - II. phase (ITMS: 313011D13) supported by The Operational Program Research and Innovation funded by the European Regional Development Fund.

\section{References}

1. A. Emadi, Y. Gao, M. Ehsan, Modern Electric, Hybrid Electric and Fuel Cell Vehicles, 1-5 / 412-416, CRC Press, (2009)

2. C. Gribben, Debunking the Myth of EVs and Smokestacks, http://www.electroauto.com/info/pollmyth.shtml

3. I. Evtimov, R. Ivanov, Proceedings of BulTrans-2009, 94, (2009)

4. P. Mock, J. German, A. Bandivadekar, I. Riemersma, Discrepancies between type-approval and "realworld" fuel consumption and $\mathrm{CO}_{2}$ values, International Council on Clean Transportation, (2012)

5. D. Barta, M. Mruzek, D. Kalincak, Proceedings of BulTrans-2013, 54, (2013)

6. B. Petkov, Theory of the automobile, tractor and car, 98-124, Tehnika, (1979)

7. D. Barta, M. Mruzek, Proceedings of ICCSTE-2015, No. 273, (2015) 